\title{
Polyesters with Built-In Threshold Temperature and Deformation Sensors
}

\author{
Maki Kinami, Brent R. Crenshaw and Christoph Weder
}

Department of Macromolecular Science and Engineering, Case Western Reserve University, 2100 Adelbert Road, Cleveland, Ohio 44106-7202

\section{Supplementary Information}
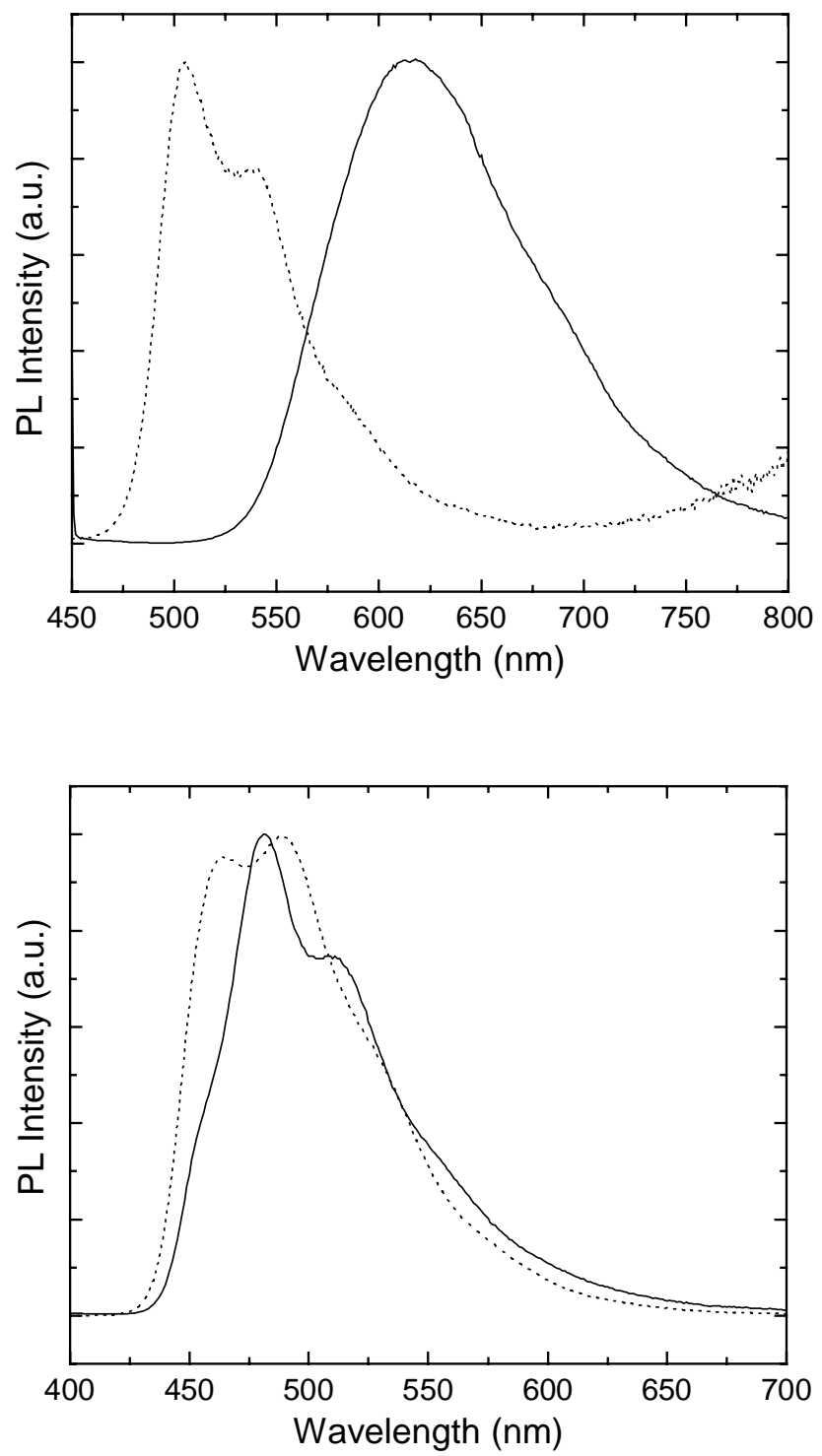

Figure S1: Normalized PL emission spectra of $\mathrm{CHCl}_{3}$ solutions (dotted line) and "as synthesized" crystals (solid line) of (top) C12-RG and (bottom) C12-YB. 

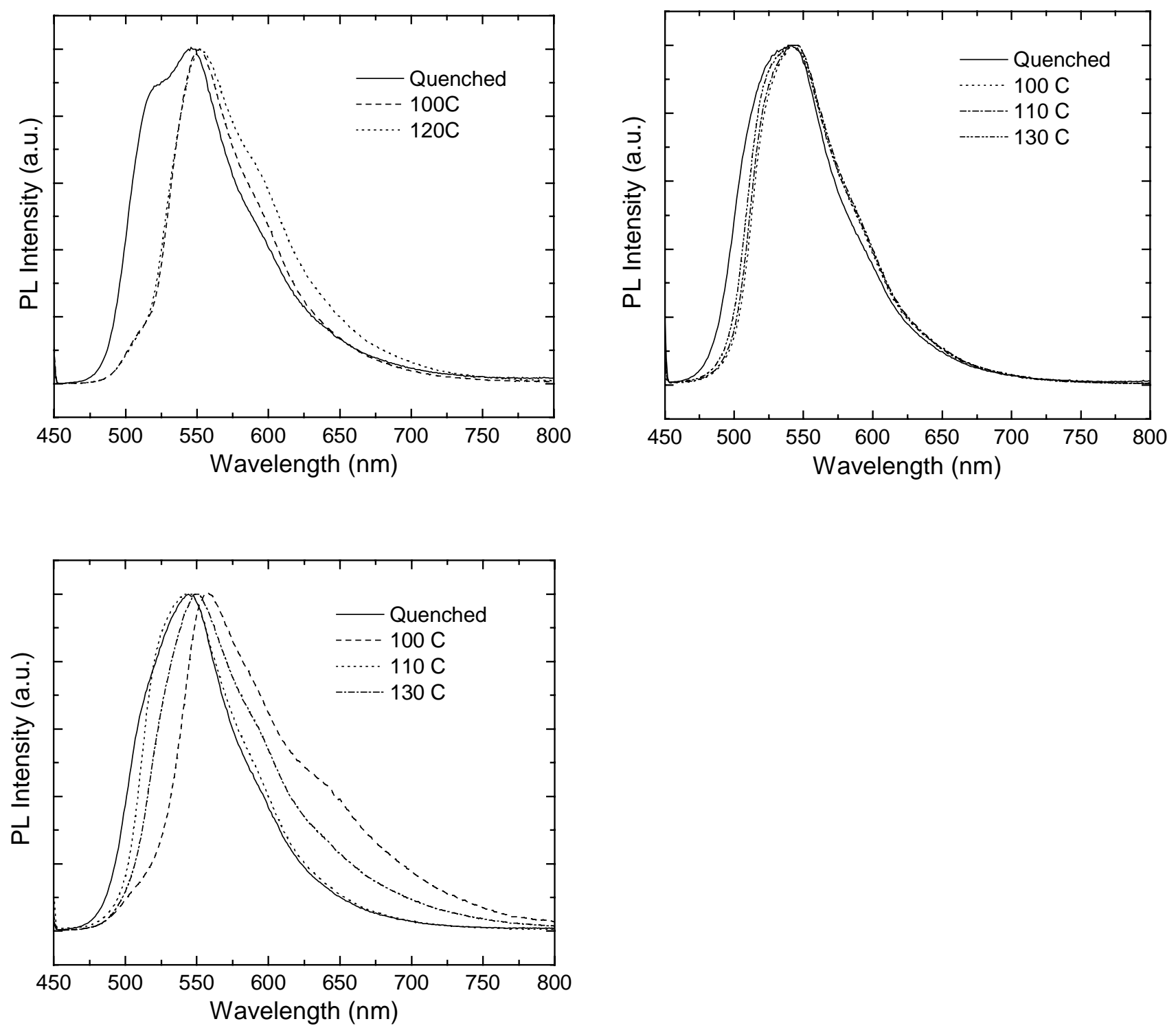

Figure S2: Normalized PL emission spectra of blend films based on PET and (top left) $1 \%$ w/w C1-RG, (top right) $0.2 \%$ w/w C18-RG, and (bottom left) $0.5 \%$ w/w C18-RG. Shown are spectra of quenched films (solid line) and samples that were annealed for $2 \mathrm{~h}$ and at the temperature indicated in the figure. 


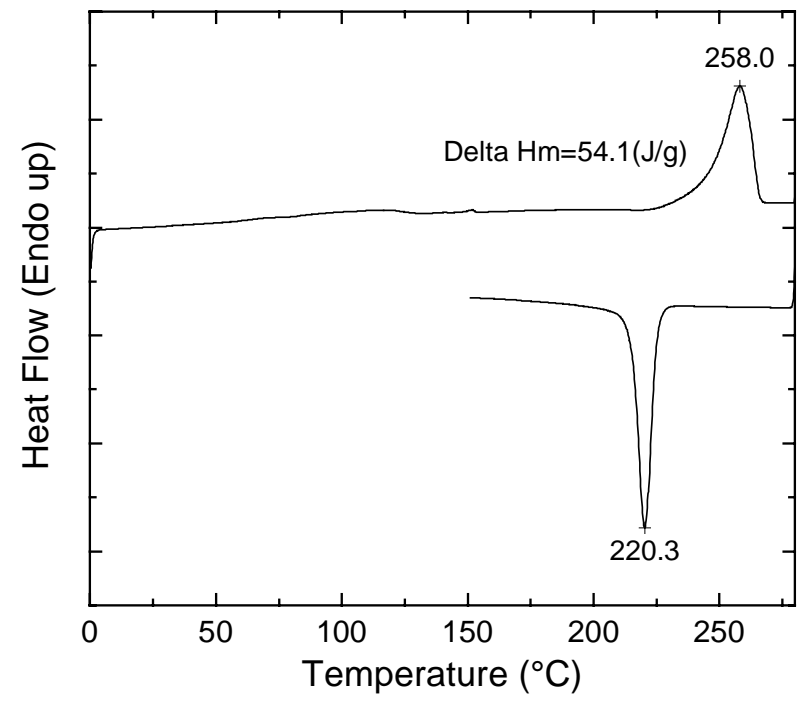

Figure S3: Differential scanning calorimetry (DSC) traces of $2 \%$ w/w PET/C18-RG blends that were annealed for $3 \mathrm{~min}$ at $100{ }^{\circ} \mathrm{C}$ prior to the DSC experiment. First heating (top curve) and cooling (bottom curve) scans were recorded at heating/cooling rates of 10 $\mathrm{K} / \mathrm{min}$. 


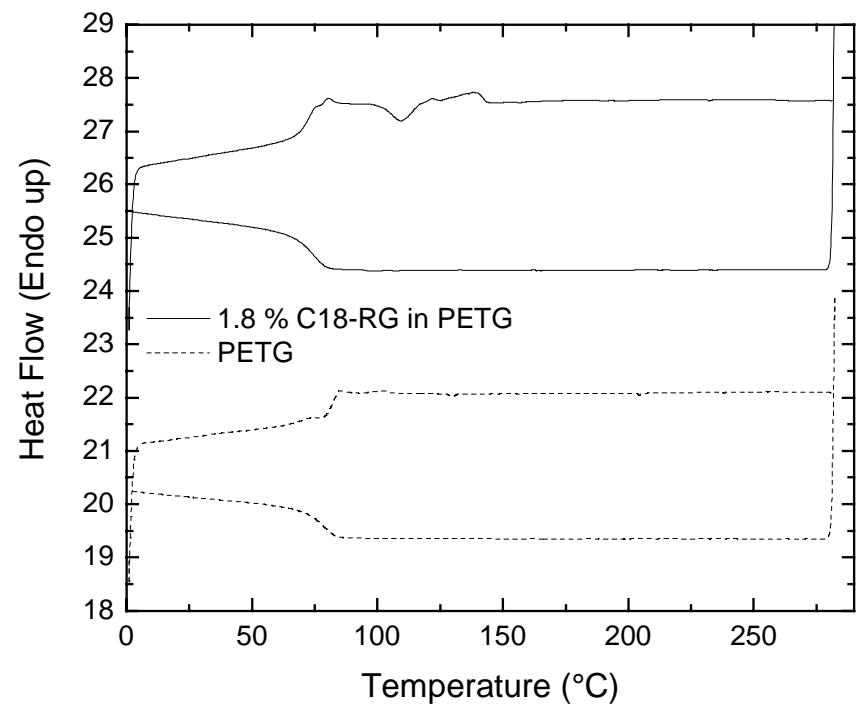

Figure S4. Differential scanning calorimetry (DSC) traces of $1.8 \%$ w/w PETG/C18-RG blend (top loop) and neat PETG (bottom loop). First heating (top curves) and cooling (bottom curves) scans were recorded at heating/cooling rates of $10 \mathrm{~K} / \mathrm{min}$. 